\title{
Exigência nutricional de metionina+cistina digestíveis para galinhas poedeiras de 54 a 70 semanas de idade
}

\author{
Edwiney Sebastião Cupertino ${ }^{1}$, Paulo Cezar Gomes ${ }^{2}$, Horacio Santiago Rostagno², Juarez \\ Lopes Donzele ${ }^{2}$, Marlene Schmidt ${ }^{3}$, Heloisa Helena de Carvalho Mello ${ }^{4}$
}

\author{
1 UFES - ES, Brasil. \\ 2 Departamento de Zootecnia - UFV, Viçosa MG, Brasil. \\ ${ }^{3}$ Alltech-Brasil. \\ ${ }^{4}$ Departamento de Zootecnia - UFV, Viçosa MG, Brasil.
}

RESUMO - Objetivou-se determinar a exigência de metionina+cistina digestíveis no período de 54 a 70 semanas de idade. Utilizaram-se 360 aves (180 Lohmann LSL e 180 Lohmann Brown) em esquema fatorial $5 \times 2$ (5 níveis de metionina+cistina digestíveis e 2 variedades) no delineamento inteiramente casualizado com 6 repetições e 6 aves por unidade experimental. Os tratamentos consistiram de dietas suplementadas com cinco níveis de DL-metionina (98\%), de forma a proporcionar 0,$492 ; 0,544 ; 0,596 ; 0,648$ e 0,700\% de metionina+cistina digestíveis. Os parâmetros avaliados foram: produção de ovos, peso dos ovos, massa de ovos, consumo de ração, consumo de metionina+cistina digestível, conversão alimentar, componentes dos ovos (albúmen, gema e casca), qualidade interna do ovo (unidades Haugh, índice de albúmen e de gema), percentual de ovos não-comerciais e variação de peso corporal. Os níveis de metionina+cistina digestíveis estudados influenciaram a produção de ovos, o peso dos ovos, a massa de ovos, o consumo de ração, o consumo de metionina+cistina digestíveis, a conversão alimentar, o peso da gema e da casca e a variação de peso corporal. As exigências de metionina+cistina digestíveis foram estimadas pelos modelos de regressão polinomial. O valor estimado para a exigência de poedeiras leves foi de $0,645 \%$ de metionina+cistina digestíveis, correspondente a um consumo de $712 \mathrm{mg} / \mathrm{ave}$.dia de metionina+cistina e $12,5 \mathrm{~g}$ de metionina+cistina digestível/g de massa de ovo produzida. Para as poedeiras semipesadas, a exigência foi de $0,655 \%$ de metionina+cistina digestíveis na dieta, correspondente a um consumo de $723 \mathrm{mg} / \mathrm{ave}$.dia de metionina+cistina e 13,2 g de metionina+cistina digestível/g de massa de ovo produzida.

Palavras-chave: aminoácidos, aves de postura, desempenho, ovos

\section{Nutritional requirement of methionine+cistine digestibles for laying hens during a period of 54 to 70 weeks of age}

\footnotetext{
ABSTRACT - This research was carried out using 360 laying hens (180 Lohmann LSL and 180 Lohmann Brown), to establish the nutritional requirement of digestible methionine+cystine in the period from 54 to 70 weeks of age. A completely randomized experimental design, in a $5 \times 2$ factorial arrangement (5 levels of digestible methionine+cystine and 2 laying hen strain), with 6 replications and 6 hens per experimental unit, was used. The treatments consisted of diets supplemented with 5 levels of DL-methionine (98\%), resulting in 0.492, 0.544, 0.596, 0.648 and $0.700 \%$ of digestible methionine+cystine in diets. The parameters analyzed were: egg production, egg weight, egg mass, feed intake, digestible methionine+cystine intake, feed conversion, egg components (albumen, yolk and shell), internal quality (Haugh unit, albumen index and yolk index), the percentage of eggs does not trade and the body weight gain. The levels of methionine+cystine digestibles studied influenced the egg production, egg weight, egg mass, feed intake, digestible methionine+cystine intake, feed conversion, weight yolk and shell, and the body weight gain. The requirements of digestible methionine+cistine were estimated by polynomial regression models. The digestible methionine+cystine requirement, estimated for the laying hens light-weight was of $0.645 \%$ in the ration, corresponding to daily intake per hen of $712 \mathrm{mg}$ and $12.5 \mathrm{~g}$ of methionine+cystine digestibles/g egg mass produced. For the laying hens semi-heavy was of $0.655 \%$ in the ration, corresponding to daily intake per hen of $723 \mathrm{mg}$ and $13.2 \mathrm{~g}$ of methionine+cystine digestibles/g egg mass produced.
}

Key Words: amino acid, eggs, laying hens, performance 


\section{Introdução}

A metionina é o principal doador do grupo metil (S-adenosilmetionina) para as diversas reações metabólicas e participa diretamente da síntese proteica (Leeson \& Summers, 2001). Serve também como fonte alternativa de cistina em um processo não-reversível, desempenhando função especial na estrutura de muitas proteínas (imunoglobulinas, hormônio insulina) e interligando cadeias polipeptídicas por meio de pontes dissulfeto (Lenningher, 1996). Em aves poedeiras, interfere de maneira significativa na produção (Waldroup \& Hellwig, 1995; Sá et al., 2007; Geraldo, 2006) e no peso dos ovos (NarváezSolarte et al., 2005; Pavan et al., 2005).

As exigências nutricionais de metionina+cistina para poedeiras em produção têm sido determinadas ao longo dos anos, embora com pouca analogia entre as recomendações. Waldroup \& Hellwing (1995) relataram que as diferenças nas determinações de metionina para poedeiras são perfeitamente compreensíveis, em razão das mudanças significativas na genética, nutrição e no manejo das aves, além dos efeitos da idade, dieta e das condições ambientais. De acordo com Filho et al. (2006), vários fatores influenciam nas exigências de metionina +cistina, como o teor de proteína da ração, a linhagem, o ambiente térmico e o teor energético, assim como a presença de fatores antinutricionais e o processamento da matériaprima utilizada na ração.

As dietas práticas à base de milho e farelo de soja são utilizadas com rotina na alimentação de aves poedeiras, e nestas rações a metionina é o primeiro aminoácido limitante. Assim, a determinação do nível adequado desse aminoácido para poedeiras é essencial, pois pode interferir de forma direta nos custos das dietas e no desempenho das aves.

Objetivou-se determinar as exigências nutricionais de metionina+cistina digestíveis em poedeiras leves e semipesadas em produção no período de 54 a 70 semanas de idade.

\section{Material e Métodos}

O experimento foi realizado nas instalações da Seção de Avicultura do Departamento de Zootecnia do Centro de Ciências Agrárias da Universidade Federal de Viçosa, Minas Gerais, no período de novembro de 2003 a fevereiro de 2004.

No experimento foram utilizadas 360 aves com 54 semanas de idade - 180 da marca comercial Lohmann LSL e 180 da marca comercial Lohmann Brown-, distribuídas em esquema fatorial $5 \times 2$, composto de 5 níveis de metionina + cistina digestíveis e 2 variedades (leves e semipesadas), em delineamento inteiramente casualizado com 6 repetições e 6 aves por unidade experimental.

As poedeiras foram criadas no piso, em galpão aberto, e foram transferidas, na $17 \underline{\text { a }}$ semana de idade, para um galpão de postura de $60 \times 9 \mathrm{~m}$ coberto com telhas de barro, alojadas aos pares, em gaiolas de $25 \times 40 \times 45 \mathrm{~cm}$.

Para determinação da exigência de metionina+cistina digestíveis, foram formuladas rações isoproteicas com um desses níveis de aminoácidos, obtidos a partir de uma dieta basal suplementada com cinco níveis de DL-metionina (98\%) em substituição ao aminoácido não-essencial L-glutâmico, de forma a proporcionar 0,492; 0,544; 0,596; 0,648; e $0,700 \%$ de metionina + cistina digestíveis e as relações (met+cist digestíveis/lisina digestível) 75; 83; 91; 99 e 107 nas rações para poedeiras leves e semipesadas (Tabela 1).

A digestibilidade dos aminoácidos sintéticos e dos demais nutrientes das rações foi determinada conforme recomendações preconizadas por Rostagno et al. (2000).

Todas as poedeiras consumiram a mesma ração até a 54a semana de idade. Antes de iniciar o fornecimento das rações experimentais, procedeu-se à distribuição das aves, padronizando-as por peso corporal e postura. O controle da produção de ovos foi realizado de modo a permitir a uniformização das aves nos tratamentos.

A partir da 54 a semana de idade, as poedeiras foram submetidas aos tratamentos, iniciando-se o período experimental, cuja duração foi de 16 semanas. As rações foram fornecidas diariamente em dois horários, às $7 \mathrm{~h}$ e às $17 \mathrm{~h}$, garantindo consumo de ração e água à vontade durante todo o período experimental.

O ensaio experimental foi dividido em quatro períodos de coletas dos ovos, cada um correspondente a 28 dias. Utilizou-se o programa de luz contínuo, com 16 horas de luz e 8 horas de escuridão. A temperatura e umidade relativa no galpão foram monitoradas duas vezes ao dia, por termômetros de máxima e mínima e de bulbo seco e úmido, distribuídos por toda a instalação, à altura das aves. Os valores médios foram de 26,2; 20,3; 23,5 e $22,9^{\circ} \mathrm{C}$, respectivamente, nos quatro períodos experimentais.

Os parâmetros avaliados foram: produção de ovos, peso dos ovos, massa de ovos, consumo de ração, consumo de metionina+cistina digestíveis, conversão alimentar, componentes dos ovos (peso de albúmen, peso de gema e percentagem de casca), qualidade interna (unidades Haugh, índice de albúmen e de gema), percentual de ovos nãocomerciais e a mudança de peso corporal. 
Tabela 1- Composições percentuais e valor nutricional das dietas experimentais

\begin{tabular}{|c|c|c|c|c|c|}
\hline \multirow[t]{2}{*}{ Ingrediente } & \multicolumn{5}{|c|}{ Nível de metionina+cistina digestíveis (\%) } \\
\hline & $\begin{array}{r}0,492 \\
\text { (basal) }\end{array}$ & 0,544 & 0,596 & 0,648 & 0,700 \\
\hline Farelo de soja & 19,800 & 19,800 & 19,800 & 19,800 & 19,800 \\
\hline Milho & 40,412 & 40,412 & 40,412 & 40,412 & 40,412 \\
\hline Farelo de trigo & 7,800 & 7,800 & 7,800 & 7,800 & 7,800 \\
\hline Sorgo baixo tanino & 17,900 & 17,900 & 17,900 & 17,900 & 17,900 \\
\hline Óleo vegetal & 2,990 & 2,990 & 2,990 & 2,990 & 2,990 \\
\hline Fosfato bicálcico & 1,255 & 1,255 & 1,255 & 1,255 & 1,255 \\
\hline Calcário & 8,890 & 8,890 & 8,890 & 8,890 & 8,890 \\
\hline Sal comum & 0,491 & 0,491 & 0,491 & 0,491 & 0,491 \\
\hline Cloreto de colina & 0,020 & 0,020 & 0,020 & 0,020 & 0,020 \\
\hline Mistura vitamínica ${ }^{1}$ & 0,100 & 0,100 & 0,100 & 0,100 & 0,100 \\
\hline Mistura mineral ${ }^{2}$ & 0,050 & 0,050 & 0,050 & 0,050 & 0,050 \\
\hline Butil-hidroxi-tolueno & 0,010 & 0,010 & 0,010 & 0,010 & 0,010 \\
\hline L-glutâmico & 0,224 & 0,171 & 0,116 & 0,063 & 0,010 \\
\hline DL-metionina & 0,058 & 0,111 & 0,166 & 0,219 & 0,272 \\
\hline Total & 100 & 100 & 100 & 100 & 100 \\
\hline
\end{tabular}

Composição calculada (aminoácidos base digestível)

\begin{tabular}{|c|c|c|c|c|c|}
\hline Proteína bruta (\%) & 15,06 & 15,06 & 15,06 & 15,06 & 15,06 \\
\hline $\begin{array}{l}\text { Energia metabolizável } \\
(\mathrm{kcal} / \mathrm{kg})\end{array}$ & 2802 & 2803 & 2804 & 2805 & 2806 \\
\hline Cálcio (\%) & 3,818 & 3,818 & 3,818 & 3,818 & 3,818 \\
\hline Fósforo disponível (\%) & 0,341 & 0,341 & 0,341 & 0,341 & 0,341 \\
\hline Sódio (\%) & 0,227 & 0,227 & 0,227 & 0,227 & 0,227 \\
\hline Potássio(\%) & 0,609 & 0,609 & 0,609 & 0,609 & 0,609 \\
\hline Metionina (\%) & 0,275 & 0,327 & 0,379 & 0,431 & 0,483 \\
\hline Metionina+cistina (\%) & 0,492 & 0,544 & 0,596 & 0,648 & 0,700 \\
\hline Lisina $(\%)$ & 0,653 & 0,653 & 0,653 & 0,653 & 0,653 \\
\hline Treonina (\%) & 0,498 & 0,498 & 0,498 & 0,498 & 0,498 \\
\hline Triptofano (\%) & 0,172 & 0,172 & 0,172 & 0,172 & 0,172 \\
\hline Arginina (\%) & 0,960 & 0,960 & 0,960 & 0,960 & 0,960 \\
\hline Leucina (\%) & 1,309 & 1,309 & 1,309 & 1,309 & 1,309 \\
\hline$(\%)$ & 0,584 & 0,584 & 0,584 & 0,584 & 0,584 \\
\hline \%) & 0,372 & 0,372 & 0,372 & 0,372 & 0,372 \\
\hline Fenilananina (\%) & 0,686 & 0,686 & 0,686 & 0,686 & 0,686 \\
\hline Metionina+cistina/lisina & 75 & 83 & 91 & 99 & 107 \\
\hline \multicolumn{6}{|c|}{$\begin{array}{l}{ }^{1} \text { Rovimix matrizes (Roche) - composição/kg: vit. A - } 12.000 .000 \text { U.I.; vit } \mathrm{D}_{3} \text { - } \\
3.600 .000 \text { U.I.; vit. E - } 3.500 \text { U.I.; vit } \mathrm{B}_{1}-2.500 \mathrm{mg} \text {; vit } \mathrm{B}_{2}-8.000 \mathrm{mg} \text {; vit } \mathrm{B}_{6} \text { - } \\
3.000 \mathrm{mg} \text {; ácido pantotênico - } 12.000 \mathrm{mg} \text {; biotina - } 200 \mathrm{mg} \text {; vit. K - } 3.000 \mathrm{mg} \text {; } \\
\text { ácido fólico - } 3.500 \mathrm{mg} \text {; ácido nicotínico - } 40.000 \mathrm{mg} \text {;it. } \mathrm{B}_{12}-20.000 \mathrm{mcg} \text {; } \\
\text { selênio - } 130 \mathrm{mg} \text {; q.s.p. }-1.000 \text { g. } \\
2 \text { Roligomix Aves (Roche) - composição/kg: manganês - } 160 \text { g; ferro - } 100 \text { g; } \\
\text { zinco - } 100 \text { g; cobre - } 20 \text { g; cobalto - } 2 \text { g; iodo - } 2 \text { g; q.s.p. - } 1.000 \text { g. }\end{array}$} \\
\hline
\end{tabular}

As análises estatísticas dos parâmetros avaliados foram realizadas utilizando-se o programa SAEG - Sistema para Análises Estatísticas e Genéticas (UFV, 1997), considerando os efeitos de variedade e os efeitos de níveis de metionina+cistina digestíveis dentro de cada variedade, decompostos nos seus efeitos lineares, quadráticos, cúbicos e quárticos.

\section{Resultados e Discussão}

Não foi observado efeito significativo $(\mathrm{P}>0,05)$ das linhagens sobre o consumo médio de ração (Tabela 2). Embora outros pesquisadores (Goulart, 1997; Narváez-
Solarte, 1996) tenham observado consumos de ração semelhantes entre as poedeiras leves e semipesadas, estes resultados contrariam ao preconizado nos manuais das linhagens (Lohmann Brown e Lohmann LSL).

Os níveis de metionina+cistina digestíveis influenciaram de forma linear $(\mathrm{P}<0,05)$ o consumo de ração das poedeiras semipesadas. Austic (1986) inferiu que elevada deficiência de metionina na dieta provoca diminuição desse aminoácido no plasma sanguíneo e nesta situação um sinal é enviado ao sistema nervoso central, que ativa os mecanismos responsáveis pela redução no consumo de alimentos. Pars \& Summers (1991) observaram que o desbalanço aminoacídico provocado pela deficiência de metionina causa efeitos negativos sobre o consumo de alimentos e sobre a taxa de crescimento em frangos de corte. Efeito semelhante de anorexia também foi observado por NarváezSolarte (1996) para poedeiras leves e semipesadas mantidas com dietas deficientes em metionina+cistina.

O consumo de metionina+cistina digestíveis aumentou de forma linear $(\mathrm{P}<0,01)$ de acordo com a concentração desses aminoácidos na dieta, tanto para poedeiras leves quanto para as semipesadas, portanto, não houve diferença significativa $(\mathrm{P}>0,05)$ entre as linhagens estudadas.

Não houve efeito significativo $(\mathrm{P}>0,05)$ dos níveis de metionina+cistina digestíveis sobre as médias de peso dos ovos das poedeiras leves e semipesadas. Contudo, efeito significativo $(\mathrm{P}<0,05)$ da variedade sobre a produção e massa de ovo foi observado e as poedeiras leves, além de produzirem mais ovos, também apresentaram maior massa de ovo em comparação às semipesadas. Nos manuais comerciais das variedades, são preconizados desempenhos produtivos (massa de ovo) semelhantes entre as aves leves e semipesadas em mesma idade, contudo, os resultados obtidos não confirmaram essa informação, o que torna possível inferir que os níveis de metionina+cistina digestíveis da dieta promovem respostas distintas nas variedades estudadas, visto que, no menor nível dietético (0,492\%), os efeitos da deficiência desses aminoácidos reduziram de forma mais significativa o consumo de ração e de aminoácidos entre poedeiras semipesadas em comparação às aves leves.

Os níveis de aminoácidos da dieta tiveram efeito linear $(\mathrm{P}<0,01)$ sobre a produção das poedeiras leves e semipesadas, o peso e massa de ovo das poedeiras semipesadas e também efeito quadrático sobre a massa $(\mathrm{P}<0,05)$ e o peso de ovo $(\mathrm{P}<0,01)$ das poedeiras leves.

Diversos pesquisadores (Novak et al., 2004; Sá et al., 2007; Geraldo, 2006) também identificaram resposta na produção de ovos de aves poedeiras ao suplementarem dietas deficientes em metionina+cistina com metionina. 
Tabela 2 - Desempenho de poedeiras leves e semipesadas de 54 a 70 semanas de idade alimentadas com rações com diversos níveis de metionina+cistina digestível

\begin{tabular}{|c|c|c|c|c|c|c|c|c|}
\hline & \multicolumn{5}{|c|}{ Nível de metionina+cistina (\%) } & & \multirow[t]{2}{*}{ Média $^{1}$} & \multirow[t]{2}{*}{$\mathrm{CV}(\%)$} \\
\hline & 0,492 & 0,544 & 0,596 & 0,648 & 0,700 & & & \\
\hline \multicolumn{9}{|c|}{ Consumo de ração (g/ave/dia) } \\
\hline Leves & 109 & 110 & 111 & 110 & 112 & ns & $110,4 \mathrm{a}$ & \multirow[b]{2}{*}{2,57} \\
\hline Semipesadas 2 & 106 & 113 & 110 & 111 & 112 & * & $110,4 \mathrm{a}$ & \\
\hline Semipesadas ${ }^{2}$ & 521,5 & 614,7 & 655,6 & 719,2 & 784,0 & $* *$ & $659,0 \mathrm{a}$ & 2,53 \\
\hline \multicolumn{9}{|c|}{ Produção de ovos por ave por dia (\%) } \\
\hline Leves $^{2}$ & 77,7 & 81,7 & 85,2 & 86,0 & 85,4 & * & $83,2 \mathrm{a}$ & 8,37 \\
\hline \multicolumn{9}{|l|}{ Peso do ovo (g) } \\
\hline Semipesadas $^{2}$ & 63,01 & 64,65 & 65,68 & 65,66 & 67,19 & $* *$ & $65,23 a$ & 2,68 \\
\hline \multicolumn{9}{|c|}{ Massa do ovo (g/ave/dia) } \\
\hline Leves $^{3}$ & 47,8 & 53,8 & 55,9 & 56,7 & 56,1 & $*$ & $54,06 \mathrm{a}$ & \multirow[b]{2}{*}{8,13} \\
\hline Semipesadas $^{2}$ & 44,8 & 48,5 & 50,8 & 54,0 & 54,8 & $* *$ & $50,58 \mathrm{~b}$ & \\
\hline
\end{tabular}

Narváez-Solarte et al. (2005) verificaram que níveis superiores a $0,684 \%$ de metionina+cistina totais na dieta podem causar efeitos negativos na produção de ovos porque também promovem desbalanço aminoacídico e ocasionam redução da síntese proteica com o aumento no catabolismo do aminoácido limitante. Entretanto, esse efeito negativo provocado por altos níveis de metionina+ cistina na dieta não foram detectados neste estudo.

Os efeitos benéficos da suplementação de metionina sobre o peso de ovos são evidentes na literatura. Pavan et al. (2005) avaliaram a influência dos níveis de metionina+cistina totais sobre o desempenho de poedeiras semipesadas de 52 a 72 semanas de idade e observaram efeito significativo dos níveis destes aminoácidos sobre o peso dos ovos, fato já relatado por Narváez-Solarte (1996), Harms (1999), Shafer et al. (1998) e Harms \& Russel (2003), que também verificaram que o peso dos ovos aumentou de acordo com os níveis de metionina+cistina na dieta. Sohail et al. (2002) testaram três níveis de metionina+cistina totais $(0,65 ; 0,72$ e $0,81 \%)$ em poedeiras leves na fase de 21 e 42 semanas de idade e observaram efeito linear dos níveis desses aminoácidos no peso dos ovos.
Os efeitos dos níveis de metionina+cistina digestíveis sobre a produção e o peso dos ovos refletiram sobre a massa de ovo, pois esta variável sofre influência direta tanto do peso quanto da produção de ovos.

A linhagem teve efeito significativo $(P<0,05)$ sobre a conversão alimentar em quilograma de ração consumida por dúzia de ovos e em quilograma de ração consumida por quilograma de ovos produzidos (Tabela 3). A taxa de conversão alimentar das poedeiras leves foi melhor que a das aves semipesadas, consequência do melhor desempenho produtivo das leves em relação às semipesadas, visto que ambas as linhagens não diferiram estatisticamente quanto ao consumo de ração. Narváez-Solarte (1996) também observou resultados semelhantes ao avaliar as exigências nutricionais de metionina+cistina para aves poedeiras de 22 a 38 semanas de idade. Todavia, Sá et al. (2007) não detectaram diferenças estatísticas nesta resposta no período de 34 a 50 semanas de idade, mas constataram que o consumo de ração das aves leves foi maior que o das semipesadas.

Considerando a conversão alimentar em quilograma de ração consumida por quilograma de ovos produzidos, foi 
Tabela 3 - Conversão alimentar e variação de peso corporal em poedeiras leves e semipesadas alimentadas com rações com diversos níveis de metionina+cistina digestíveis na fase de 54 a 70 semanas de idade

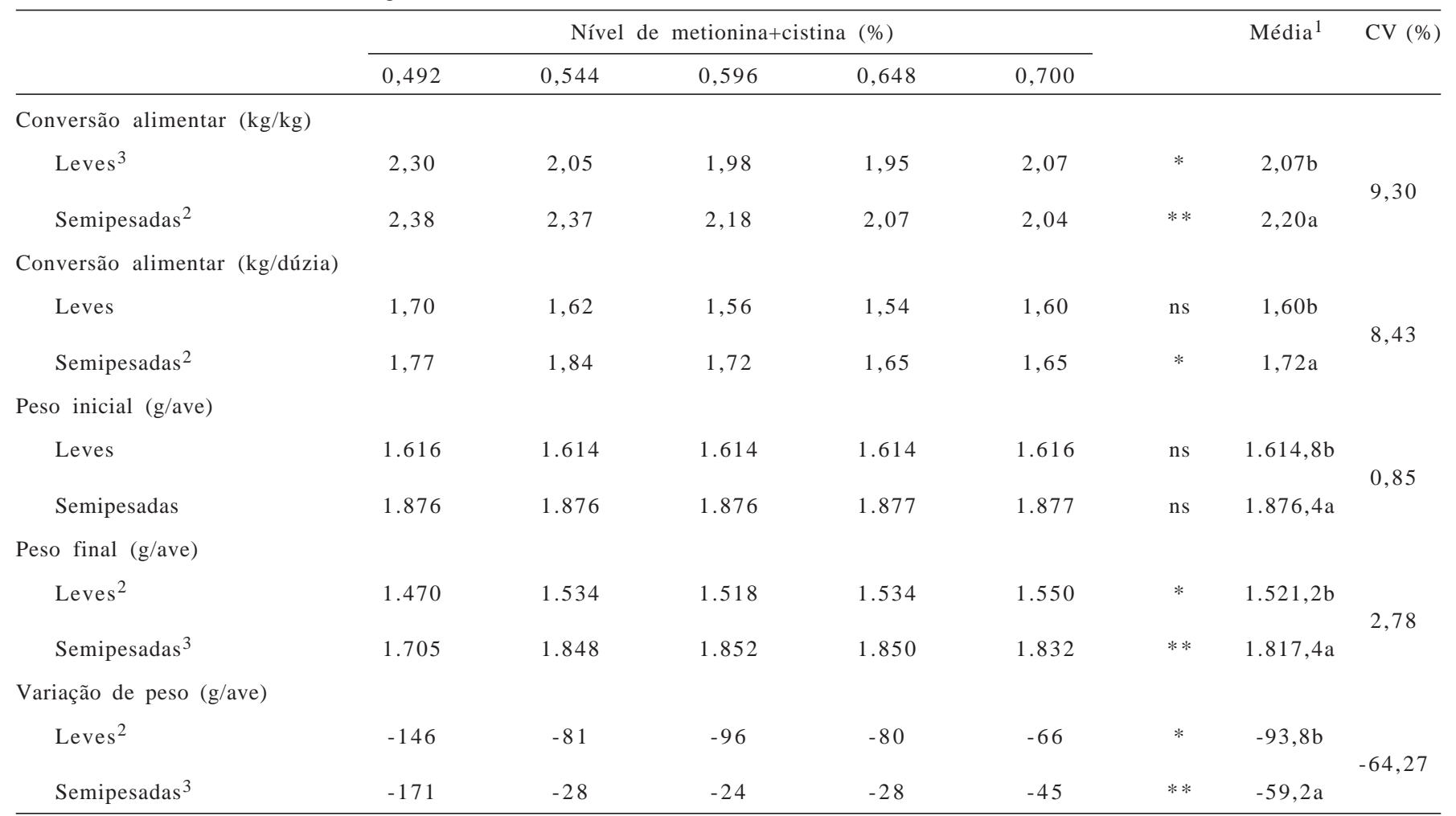

${ }_{1}^{1}$ Médias seguidas pela mesma letra na coluna, dentro de cada parâmetro, não diferem entre si a 5\% de probabilidade pelo teste F.

2 Efeito linear.

${ }^{3}$ Efeito quadrático.

$\mathrm{CV}$ - coeficiente de variação.

** $(\mathrm{P}<0,01) ; * \mathrm{P}(<0,05)$; ns $\mathrm{P}(>0,05)$ pelo teste $\mathrm{F}$.

observado efeito quadrático $(\mathrm{P}<0,05)$ dos níveis de metionina+cistina digestíveis nas aves leves e efeito linear $(\mathrm{P}<0,01)$ nas poedeiras semipesadas. Quando a conversão alimentar foi calculada em quilograma de ração consumida por dúzia de ovos, foi observado efeito linear $(\mathrm{P}<0,05)$ dos níveis destes aminoácidos para as poedeiras semipesadas.

Houve melhora considerável na eficiência de utilização da ração para a produção de ovos, com o aumento dos níveis de metionina+cistina digestíveis da dieta. Diversos autores (Waldroup \& Hellwig, 1995; Rodrigues et al., 1996; Geraldo, 2006) também observaram essa melhora quando suplementaram rações deficientes em aminoácidos sulfurosos com níveis crescentes de metionina e atribuíram esses resultados ao melhor equilíbrio aminoacídico.

Não houve diferença significativa $(\mathrm{P}>0,05)$ no peso corporal inicial das aves, evidenciando que esta variável não influenciou os resultados experimentais.

Em ambas as linhagens, foi observada perda de peso corporal no final do período experimental, porém essa perda foi mais acentuada nas poedeiras leves. Essa maior perda de peso corporal das aves leves provavelmente foi consequência da produção de ovos (5,7\% superior à das poedeiras semipesadas).

Os níveis de metionina+cistina digestíveis da dieta proporcionaram efeito quadrático $(\mathrm{P}<0,05)$ e linear $(\mathrm{P}<0,01)$ sobre a perda de peso das aves semipesadas $\mathrm{e}$ leves, respectivamente. Embora a perda de peso corporal tenha sido observada em todos os níveis de aminoácidos testados, ocorreu de forma mais significativa quando as poedeiras leves e semipesadas foram alimentadas com os menores níveis de metionina+cistina digestíveis (0,492\%), provavelmente porque o desbalanço aminoacídico foi mais acentuado. Harms \& Russel (2003) testaram níveis crescentes de metionina $(0,20$ a $0,34 \%)$ e também notaram maior perda de peso corporal nas poedeiras leves alimentadas com rações contendo os mais baixos níveis de metionina.

A perda de peso corporal ao final do período experimental contraria a recomendação descrita nos manuais das variedades, visto que são previstos acréscimos no peso corporal das aves entre 54 e 70 semanas de idade. Comparando o peso final médio obtido às 70 semanas de idade (leves: 1,521 kg; semipesadas: $1,817 \mathrm{~kg}$ ) ao previsto (leves: $1,777 \mathrm{~kg}$; semipesadas: 2,020 kg), observou-se considerável diferença 
das recomendações para as linhagens. Um dos fatores que pode ter contribuído para esse fenômeno provavelmente foi o nível de proteína bruta $(15,0 \%)$ usado nas dietas experimentais. Penz \& Jensen (1991) não observaram diferenças significativas na produção de ovos de poedeiras leves quando testaram dois níveis de proteína bruta (13\% vs $16 \%$ ), mas constataram menor peso de ovos e menor ganho de peso corporal nas poedeiras alimentadas com rações com o menor nível proteico, mesmo suplementadas com os aminoácidos que se tornaram limitantes.

Houve efeito significativo $(\mathrm{P}<0,05)$ da linhagem sobre as diversas variáveis de qualidade do ovo avaliadas, uma vez que poedeiras leves apresentaram melhores resultados de unidades Haugh e índice de albúmen (Tabela 4), porém com menor índice de gema, em comparação às semipesadas.
Esses resultados confirmam parcialmente os de Sá et al. (2007), que também verificaram que os ovos de poedeiras leves (Lohmann LSL) apresentaram valores superiores de unidades Haugh e índice de albúmen em comparação aos de poedeiras semipesadas (Lohmann Brown) no período de 34 a 50 semanas de idade. Esses autores, no entanto, não observaram diferenças significativas no índice de gema entre as variedades. Narváez-Solarte (1996), por sua vez, não constatou essas diferenças de qualidade interna entre ovos de poedeiras leves e semipesadas.

Não foi observado efeito significativo $(\mathrm{P}>0,05)$ dos níveis de metionina+cistina digestíveis sobre a qualidade interna dos ovos. Esses resultados confirmam os obtidos por Novak \& Scheideler (2004), que também não constataram efeito dos níveis de ingestão de metionina+cistina (635 a

Tabela 4 - Qualidade do ovo e componentes do ovo de poedeiras leves e semipesadas de 54 a 70 semanas de idade alimentadas com rações com diversos níveis de metionina+cistina (\%) digestíveis

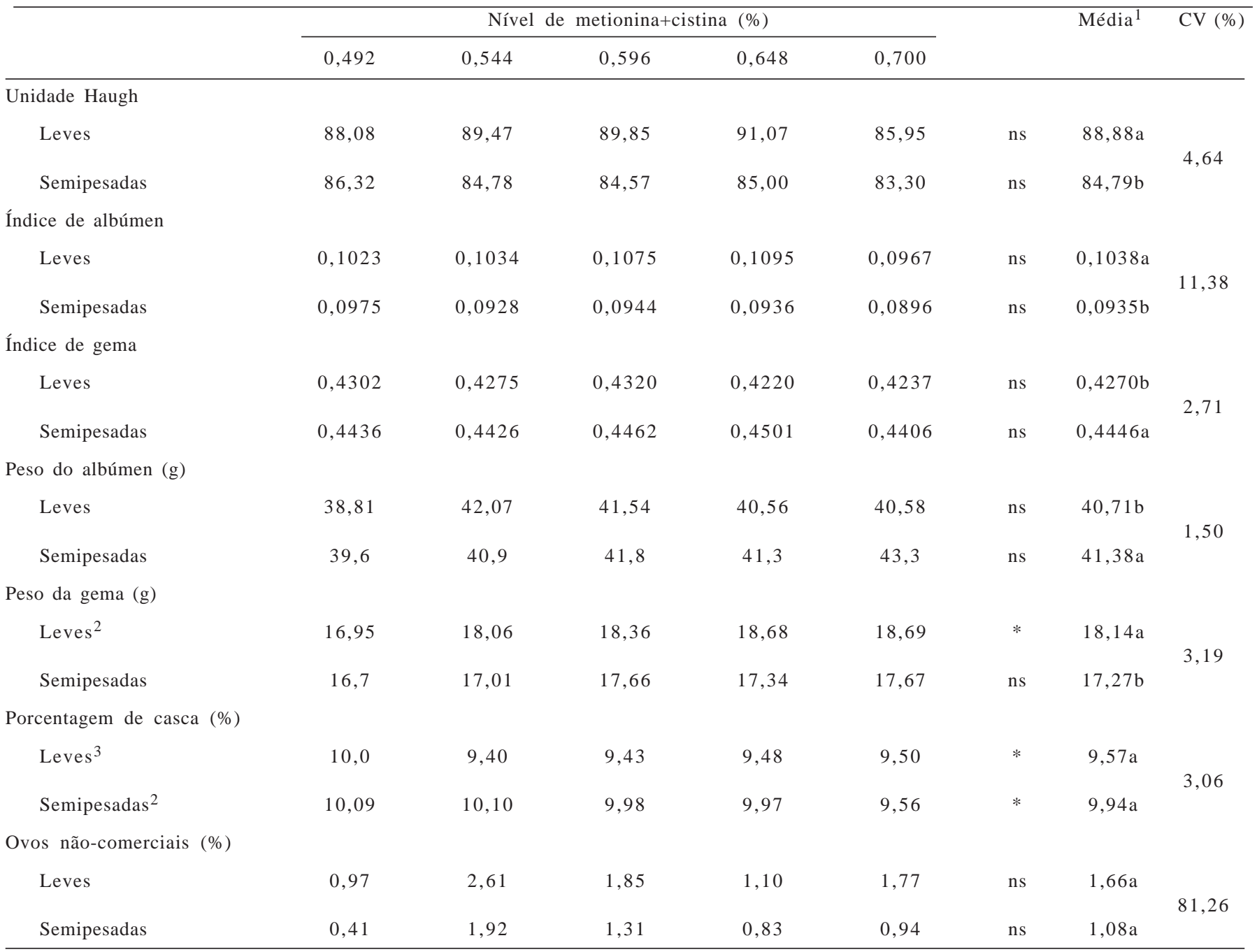

${ }^{1}$ Médias seguidas pela mesma letra na coluna, dentro de cada parâmetro, não diferem entre si a 5\% de probabilidade pelo teste F.

2 Efeito linear.

3 Efeito quadrático.

$\mathrm{CV}$ - coeficiente de variação.

** $(\mathrm{P}<0,01) ; * \mathrm{P}(<0,05)$; ns $\mathrm{P}(>0,05)$ pelo teste $\mathrm{F}$. 
$877 \mathrm{mg} / \mathrm{ave} / \mathrm{dia}$ ) sobre as unidades Haugh. Entretanto, discordam dos resultados obtidos por Narváez-Solarte et al. (2005), que perceberam melhora nas unidades Haugh à medida que reduziram os níveis de metionina+cistina da dieta.

Houve efeito da variedade $(\mathrm{P}<0,05)$ sobre os componentes internos dos ovos, pois os ovos das poedeiras leves apresentaram menor quantidade de albúmen e maior quantidade de gema em comparação aos ovos das aves semipesadas. Essas diferenças na relação gema:albúmen entre os ovos das aves leves e semipesadas podem estar relacionadas a fatores genéticos (Ahn et al., 1997; Tharrington et al.,1999).

Não houve efeito significativo $(\mathrm{P}>0,05)$ dos níveis de metionina+cistina digestíveis sobre o peso do albúmen dos ovos das poedeiras leves e semipesadas e sobre o peso da gema dos ovos das aves semipesadas. Entretanto, os níveis destes aminoácidos tiveram efeito linear $(\mathrm{P}<0,01)$ sobre a quantidade de gema dos ovos das aves leves.

Diversos pesquisadores (Prochaska et al., 1996; Shafer et al., 1998; Harms \& Russel, 2003; Novak \& Scheideler, 2004) comprovaram aumento nos componentes internos dos ovos (gema e albúmen) ocasionado pelo nível de metionina da dieta, mas seus resultados não foram confirmados estatisticamente neste estudo, exceto para o peso de gema dos ovos de poedeiras leves. Contudo, embora não se tenha detectado efeito, os resultados numéricos evidenciaram redução na quantidade de albúmen e de gema nas aves alimentadas com a ração contendo o menor nível desses aminoácidos (0,492\%).

Foi observado efeito quadrático e linear $(\mathrm{P}<0,05)$ dos níveis de metionina+cistina digestíveis da dieta sobre o percentual de casca dos ovos das poedeiras leves e semipesadas, respectivamente. À medida que aumentaram os níveis desses aminoácidos na dieta houve redução no percentual de casca, possivelmente consequência do aumento no tamanho dos ovos. Entretanto, não houve reflexo significativo $(\mathrm{P}>0,05)$ desta redução no percentual de casca do ovo sobre a incidência de ovos não-comerciais.

As exigências de metionina+cistina digestíveis foram estimadas em 0,633 e $0,645 \%$ para as aves leves, correspondentes a consumo diário de 698 e 712 mg/ave, considerando as variáveis de peso e massa de ovo, respectivamente, com consumo de ração médio de 110,4 g/ave/dia (Tabela 5). Para as poedeiras semipesadas, as exigências foram estimadas em 0,651 e 0,655\%, correspondentes a consumo diário de 718 e 723 mg/ave, considerando as variáveis produção e massa de ovo, respectivamente, com consumo de ração médio de 110,4 g/ave/dia (Tabela 6).

Os resultados encontrados neste estudo para as exigências de metionina+cistina para melhor desempenho produtivo são superiores aos recomendados pelo NRC (1994).

Tabela 5 - Exigência em metionina+cistina digestíveis, coeficientes de determinação e equações de predição ajustadas para as diversas variáveis avaliadas de poedeiras leves de 54 a 70 semanas de idade estimadas pelo modelo quadrático

\begin{tabular}{|c|c|c|c|c|c|}
\hline \multirow{3}{*}{ Variável } & \multicolumn{5}{|c|}{ Modelo quadrático } \\
\hline & \multirow[t]{2}{*}{ Equação ajustada } & \multicolumn{2}{|c|}{ Exigência } & \multirow[t]{2}{*}{ Relação } & \multirow[t]{2}{*}{$\mathrm{r}^{2}$} \\
\hline & & $(\%)$ & (mg/ave/dia) & & \\
\hline $\mathrm{PO}^{1}(\mathrm{~g})$ & $\hat{\mathrm{Y}}=-21,5566+277,944 \mathrm{~N}-219,384 \mathrm{~N}^{2}$ & 0,633 & 698 & 96 & 0,85 \\
\hline $\mathrm{MO}^{2}$ (g/ave/dia) & $\hat{\mathrm{Y}}=-101,516+491,610 \mathrm{~N}-380,956 \mathrm{~N}^{2}$ & 0,645 & 712 & 98 & 0,98 \\
\hline $\mathrm{CAK}^{3}(\mathrm{~kg} / \mathrm{kg})$ & $\hat{\mathrm{Y}}=9,86542-25,4923 \mathrm{~N}+20,51372 \mathrm{~N}^{2}$ & 0,621 & 685 & 95 & 0,98 \\
\hline $\mathrm{PC}^{4}(\%)$ & $\hat{\mathrm{Y}}=24,6721-49,6666 \mathrm{~N}+40,2531 \mathrm{~N}^{2}$ & 0,616 & 680 & 94 & 0,87 \\
\hline
\end{tabular}

${ }^{1}$ peso de ovo; ${ }^{2}$ massa de ovo; ${ }^{3}$ conversão alimentar; ${ }^{4}$ percentual de casca.

Tabela 6 - Exigência em metionina+cistina digestíveis, coeficientes de determinação e equações de predição ajustadas para as diversas variáveis avaliadas de poedeiras semipesadas de 54 a 70 semanas de idade estimadas pelo modelo LRP

\begin{tabular}{|c|c|c|c|c|c|c|}
\hline \multirow{3}{*}{ Variável } & \multicolumn{6}{|c|}{ Modelo linear Response Plateou } \\
\hline & \multirow[t]{2}{*}{ Equação ajustada } & \multirow[t]{2}{*}{ Platô } & \multicolumn{2}{|c|}{ Exigência } & \multirow[t]{2}{*}{ Relação } & \multirow[t]{2}{*}{$r^{2}$} \\
\hline & & & $(\%)$ & (mg/ave/dia) & & \\
\hline $\mathrm{OAD}^{1}(\mathrm{~g})$ & $\hat{\mathrm{Y}}=38,31923+67,1153 \mathrm{~N}$ & $\hat{\mathrm{Y}}=82,01$ & 0,651 & 718 & 100 & 0,97 \\
\hline $\mathrm{MO}^{2}$ (g/ave/dia) & $\hat{\mathrm{Y}}=16,9853+57,1923 \mathrm{~N}$ & $\hat{\mathrm{Y}}=54,44$ & 0,655 & 723 & 100 & 0,99 \\
\hline $\mathrm{CAK}^{3}(\mathrm{~kg} / \mathrm{kg})$ & $\hat{\mathrm{Y}}=3,3550-1,9187 \mathrm{~N}$ & $\hat{\mathrm{Y}}=2,05$ & 0,677 & 747 & 103 & 0,78 \\
\hline
\end{tabular}

${ }^{1}$ produção de ovos/ave/dia; ${ }^{2}$ massa de ovo; ${ }^{3}$ conversão alimentar. 
Considerando os resultados para máxima produção de massa de ovo na avaliação da melhor relação metionina+ cistina digestível/lisina digestível, obtiveram-se os valores de 98 para as aves leves e de 100 para as semipesadas. Essas relações são próximas às recomendadas por Sá et al. (2007), de 101 para aves leves e semipesadas, e de Novak et al. (2004), de 95 para poedeiras leves. Todavia, são superiores às recomendadas pelo NRC (1994), de 84, e Rostagno et al. (2005), de 91, tanto para aves leves quanto para semipesadas.

Ressalta-se que diversos fatores podem interferir na resposta produtiva das aves e consequentemente nos níveis nutricionais recomendados, por exemplo, a idade (Grobas et al. 1999), a genética utilizada (Tharrington et al., 1999), a temperatura ambiental, o método estatístico utilizado nas análises (Jansman \& Klis, 2002) e as próprias variáveis consideradas na determinação da exigência (Goulart, 1997).

As exigências em metionina+cistina digestíveis estimados pelo modelo quadrático para poedeiras leves, considerando o melhor índice de conversão alimentar, foram de $0,621 \%$, o que corresponde a consumo diário de $685 \mathrm{mg} /$ ave, com consumo de ração médio de 110,4 g/ave/dia (Tabela 5). Para as poedeiras semipesadas, essas exigências foram de $0,677 \%$ e equivalem a consumo diário de $747 \mathrm{mg} / \mathrm{ave}$, estimado pelo modelo Linear Response Plateau (LRP) considerando o mesmo índice de conversão alimentar e para mesmo consumo (Tabela 6).

\section{Conclusões}

Considerando a importância econômica da massa de ovo e o fato de esta variável ser composta pelo peso e pela produção de ovos, poedeiras leves necessitam de 0,645\% de metionina+cistina digestíveis na dieta, que corresponde a um consumo diário de $712 \mathrm{mg}$ /ave e 12,5 g de metionina+cistina digestíveis/g de massa de ovo produzida, respectivamente, e uma relação metionina+cistina/lisina de 98. A exigência de poedeiras semipesadas, para a mesma resposta, é de $0,655 \%$ de metionina+cistina digestíveis na dieta, correspondente a consumo diário de $723 \mathrm{mg} / \mathrm{ave}$ e 13,2g de metionina+cistina digestíveis/g de massa de ovo produzida, respectivamente, e relação metionina+cistina/ lisina de 100.

\section{Literatura Citada}

AHN, D.U.; KIM, S.M.; SHU, H. Effect of egg size and strain and age of hens on the solids content of chicken eggs. Poultry Science, v.76, p.914-919, 1997.

AUSTIC, R.E. Biochemical description of nutritional effects. In: FISHER, C.; BOORMAN, K.N. (Eds.) Nutrient requirements of poultry and nutritional research. London: Butterworths, 1986. p.59-77.
FARIA, D.E.; JUNQUEIRA, O.M.; SOUZA, P.A. et al. Desempenho, temperatura corporal e qualidade de ovos de poedeiras alimentadas com vitaminas D e C em três temperaturas ambiente. Revista Brasileira de ciência Avícola, v.3, p.49-56, 2001.

FILHO, J.J.; SILVA, J.H.V.; SILVA, E.L. et al. Exigências nutricionais de metionina+cistina para poedeiras semipesadas do início de produção até o pico de postura. Revista Brasileira de Zootecnia, v.35, n.3, p.1063-1069, 2006 (supl.)

GERALDO, A. Aminoácidos sulfurosos, lisina, e treonina digestíveis para poedeiras comerciais leves em produção. 2006. 189f. Tese (Doutorado em Zootecnia) - Universidade Federal de Lavras, 2006, Lavras.

GOULART, C.C. Exigência nutricional de lisina para poedeiras leves e semipesadas. 1997. 51f. Dissertação (Mestrado em Zootecnia) - Universidade Federal de Viçosa, Viçosa, MG, 1997.

GROBAS, S.; MENDEZ, J.; DE BLAS, G. et al. Influence of dietary energy, suplemental fat and linoleic acid concentration on performance of laying hens at two ages. British Poultry Science, v.40, p.681-687, 1999.

HARMS, R.H. Proteína (aminoácidos) para poedeiras. In: SIMPÓSIO INTERNACIONAL SOBRE NUTRIÇÃO DE AVES, 1999, Campinas. Anais... Campinas: 1999. p.111-122.

HARMS, R.H.; RUSSEL, G.B. Performance of commercial laying hens fed diets with various levels of methionine. Journal of Applied Poultry Research, v.12, p.449-455, 2003.

JANSMAN, A.J.M.; KLIS, J.D. Evaluation of the amino acid requirements in laying hens. In: CONFERENCE EUROPEAN POULTRY, 11., 2002, Bremen. Anais... Bremen: Conference European Poultry. (CD-ROM).

LEESON, S.; SUMMERS J.D. Nutrition of the chicken. 4.ed. Guelph: University Books, 2001. 591p.

LENNINGHER, A.L. Princípios de bioquímica. 2.ed. São Paulo: Sarvier, 1996. 839p.

NARVÁEZ-SOLARTE, W.V. Exigências em metionina+cistina para poedeiras leves e semipesadas. 1996. $57 \mathrm{f}$. Dissertação (Mestrado em Zootecnia) - Universidade Federal de Viçosa, Viçosa, MG, 1996.

NARVÁEZ-SOLARTE, W.V.; ROSTAGNO, H.S.; SOARES, P.R. Nutritional requirements in methionine + cystine for white-egg laying hens during the first cycle of production. International Journal of Poultry Science, v.4, n.12, p.965-968, 2005.

NATIONAL RESEARCH COUNCIL - NRC. Nutrient requiriments of poultry. 9.ed. Washington, D.C.: National Academy of Sciences, 1994. 155p.

NOVAK C.; YAKOUT, H.; SCHEIDELER, S. The combined effects of dietary lysine and total sulfur amino acid level on egg production parameters and egg components in dekalb delta laying hens. Poultry Science, v.83, p.977-984, 2004.

PARS, J.F.; SUMMERS, J.D. The effects of minimizing amino acid excess in broiler diets. Poultry Science, v.70, p.1540-549, 1991.

PAVAN, A.C.; MÓRI, C.; GARCIA, E.A. et al. Níveis de proteína bruta e de aminoácidos sulfurosos totais sobre o desempenho, a qualidade dos ovos e a excreção de nitrogênio de poedeiras de ovos marrons. Revista Brasileira de Zootecnia, v.34, n.2, p.568-57, 2005.

PROCHASKA, J.F.; CAREY, J.B.; SHAFER, D.J. The effect of L-lysine intake on egg component yield and composition in laying hens. Poultry Science, v.75, p.1268-1077, 1996.

RODRIGUES, P.B.; BERTECHINI, A.G.; OLIVEIRA, B.L. et al. Fatores nutricionais que influenciam a qualidade do ovo no segundo ciclo de produção e níveis de aminoácidos sulfurosos totais Revista Brasileira de Zootecnia, v.25, n.2, p.249-260, 1996. ROSTAGNO, H.S.; ALBINO, L.F.T.; DONZELE, J.L. et al. Tabelas brasileiras para aves e suínos: composição de alimentos e exigências nutricionais. 1.ed. Viçosa, MG: Editora UFV, 2000. 141p.

ROSTAGNO, H.S.; ALBINO, L.F.T.; DONZELE, J.L. et al. Tabelas brasileiras para aves e suínos: composição de alimentos e exigências nutricionais. 2.ed. Viçosa, MG: Editora UFV, 2005. 186p. 
SÁ, L.M.; GOMES, P.C.; ALBINO, L.F.T. et al. Exigência nutricional de metionina + cistina digestível para galinhas poedeiras no período de 34 a 50 semanas de idade. Revista Brasileira de Zootecnia, v.36, n.6, p.1837-1845, 2007.

SCHUTTE, J.B.; WEERDEN, E.J.; Van BERTRAM, H.L. Sulphur amino acid requirement of laying hens and the effects of excess dietary methionine on laying performance. British Poultry Science, v.24, p.319-26, 1983.

SCHUTTE, J.B.; JONG, J.; BERTRAM, H.L. Requirements of the laying hen for sulfur amino acids. Poultry Science, v.73, p.274-280, 1994.

SHAFER, D.J.; CAREY, J.B.; PROCHASKA, J.F. Dietary methionine intake on egg component yield, composition, functionality and texture profile analysis. Poultry Science, v.77, p.1056-1062, 1998.
SOHAIL, S.S.; BRYANT, M.M.; ROLAND, D.A. Influence of supplemental lysine, isoleucina, threonine, triptophan and total sulfur amino acids on egg weight of Hy-Line W-36 hens. Poultry Science, v.81, p.1038-1044, 2002.

THARRINGTON, J.B.; CURTIS P.A.; JONES, F.T. et al. Comparison of physical quality and composition of eggs from historic strains of single comb White Leghorn chickens. Poultry Science, v.78, p.591-594, 1999.

UNIVERSIDADE FEDERAL DE VIÇOSA - UFV. Central de Processamento de Dados - UFV/CPD. SAEG - Sistema para Análises Estatísticas e Genéticas. versão 7.0 Viçosa, MG: Universidade Federal de Viçosa, 1997. 59p.

WALDROUP, P.W.; HELLWIG, H.M. Methionine and total sulfur amino acid requirements influenced by stage of production. Journal Applied Poultry Science, v.4, p.283-292, 1995. 